\title{
PENGARUH PENGUASAAN AKUNTANSI DAN INOVASI WIRAUSAHA TERHADAP KINERJA MANAJERIAL PADA PERUSAHAAN JASA DI KOTA MANADO (STUDI PADA BIRO PERJALANAN TRAVEL DI KOTA MANADO)
}

\author{
Giovani Herman ${ }^{1}$, Inggriani Elim ${ }^{2}$, Victorina Z. Tirayoh ${ }^{3}$ \\ 1,2,3 Jurusan Akuntansi, Fakultas Ekonomi dan Bisnis,Universitas Sam Ratulangi, Jl. Kampus Bahu, Manado, \\ 95115, Indonesia \\ E-mail : giovaniherman86@gmail.com
}

\begin{abstract}
Recent developments in the economy in Indonesia have led to an increasingly increasing accounting role that demands accounting that can provide the financial information needed by society in making economic decisions. It is now increasingly recognized by entrepreneurs. Accounting also greatly facilitates the smoothness of management tasks. This research was conducted at 30 travel agency service companies (travel) located in Manado city. The purpose of this research is to examine the influence of the mastery of accounting and entrepreneurial innovation on managerial performance in travel agency services company in Manado city. The analytical method used is multiple linear regression analysis method with the help of SPSS 12.0 software. Based on multiple linear regression analysis. The result of the research shows that Accounting Mastery (X1) has an effect on Managerial Performance (X2) in Travel Service Company in Manado City, and Entrepreneurial Innovation also has an effect on Managerial Performance in Service Company of Travel Bureau in Manado City. This shows that the variable of Accounting Mastery (X1) and Entrepreneurial Innovation (X2) together have a significant influence on Managerial Performance variables (Y). at Travel Service Company (Travel) in Manado City. so it can be concluded that Ha accepted and rejected $\mathrm{HO}$ or can be said that the variable of Accounting Mastery and Entrepreneurial Innovation Variables affect the variable of Managerial Performance in Travel Service Company (Travel) d Manado City.
\end{abstract}

Keywords: Accounting, Innovation, Entrepreneurship, Managerial Performance.

\section{PENDAHULUAN}

Manajer atau pemilik korporasi dunia di Indonesia sekarang di tandai kemuraman. walaupun belum pasti, sebagian manager puncak dan manager keuangan memiliki strategi berkendala maka akan dihadapkan pada jalur hukum, dikarenakan penyimpangan atau mismanagemen. maka itu, cara yang dibutuhkan pada dunia kerja sekarang yaitu tindakan yang didapatkan dari panggilan dalam menerima suasana kerja yang bagus, yang dikerjakan dengan baik dan tidak ada hambatan dan harus teliti, maka dikatakan secara terus-menerus dalam menghasilkan kualitas yang lebih baik kedepanya.

Dalam literatur manajemen salah satunya, mempertimbangkan adanya inovasi jangka panjang pada kinerja organisasi dalam lingkungan yang kontemporer (Clark \& Fujimoto,2010). Teknologi, kesempatan usaha, modal,dan metodologi merupakan variabel yang mempengaruhi praktek inovasi dalam suatu organisasi.

Penguasaan akuntansi dapat diartikan sebagai penguasaan tentang perangkat pengetahuan dan sistem pemberitahuan dan mendapatkan pemberitahuan keuangan terhadap orang-orang penting dengan aktifitas ekonomi dengan situasi perusahaan. Orang yang memakai informasi tersebut ialah manajer dalam menjalankan pemeriksaan perusahaan. Pengertian inovasi adalah memberitahukan ide baru, barang baru, pelayanan baru dan cara 
baru yang lebih berguna. Wirausaha saat ini yang berperan dalam mengaplikasikan inovasi tersebut dalam mencapai tujuan. Semua itu berhubungan pada materi kinerja manajerial yang di katakan Stoner pada Juniarti (2011) ukuran apakah efektif atau efisien manajer suda bekerja dalam memenuhi tujuan perusahaan.

\section{TINJAUAN PUSTAKA}

Pengertian Akuntansi. Akuntansi yaitu sebuah pelaksanaan jasa. Maksudnya yaitu memberikan pemberitahuan kuantitatif, yang bersifat keuangan tentang entitas ekonomi dan dimaksudkan maka pakai pada pengambilan keputusan ekonomi, sebagai dasar untuk menentukan pada beberapa alternatif. (Krismiaji Y Anni Ariani). Akuntansi juga bisa disebut sistem informasi dan bisa menghasilkan laporan bagi pihak-pihak yang mempunyai kepentingan terhadap aktivitas ekonomi dan kondisi perusahaan. (Warren dkk 2014).

Inovasi. Inovasi sebagai tujuan strategis perusahaan atau negara harus dikelola sedemikian rupa sehingga bisa diimplementasikan dan berdampak pada keberlanjutan perusahaan pada level mikro, yang secara agregat akan memengaruhi kesejahteraan serta daya saing negara secara secara makro. (Arman Hakim Nasution dan Hermawan Kartajaya, 2018).

\section{Wirausaha}

Definisi Wirausaha. Wirausaha yaitu mereka yang kreatif pada masalah hidup, cara ini bisa membuat mereka tabah dan bisa menyelesaikan hambatan dalam menjadi wirausaha yang sukses. (Sadono Sukirno, et al, 2004). Kewirausahaan adalah hasil dari suatu disiplin serta proses sistematis penerapan kreatifitas dan inovasi dalam memenuhi kebutuhan dan peluang pasar. (Thomas Zimmerer, 1996).

Pengertian Inovasi Wirausaha. Inovasi wirausaha ialah menunjukan ide sesuatu yang baru, pelayanan baru, dan strategi baru yang semakin berguna yang ditunjukan oleh wirausaha itu sendiri dengan cara memberikan kerja bagi orang lain. Dan untuk memberikan kerja kepada pihak lain bisa dibentuk dengan cara mandirikan, memajukan, memajukan perusahaan langkah demi langkah, mencaritau kelemahan, kelebihan kita sebelum berbuat lebih jauh dan berani menanggung masalah sendiri dalam memiliki peluang usaha yang kreatif memilih kemampuan diri sendiri dalam mengenali barang atau produk, mengembangkan,dan menetapkan cara pendapatanya, mengatur operasi dalam pmilihan produk, menjual produknya, dan menyusun pemodalan operasinya. (Peter Drucker, 2011).

Kinerja Manajerial. Kinerja Manajerial yaitu sebuah bukti kerja yang di dapat orang tersebut pada tindakan-tindakan manajer dan mencakup perencanaan, investigasi, koordinasi, evaluasi, penjagaan, aturan staff (staffing), negoisasi, dan perwakilan representasi. (Hansen/Women).

Hubungan Penguasaan Akuntansi, inovasi Wirausaha Pada Kinerja Managerial. Para wirausaha harus memiliki pemberitahuan yang jelas, bermanfaat, dan disiplin waktu dalam mengambil kebijakan-kebijakan keuangan yang akurat. meskipun sebagian manager sebagai ahli dalam akuntansi, tetapi harus tetap membutuhkan penguasaan terhadap keuangan pokok, mencakup deretan laba/rugi, neraca, dan cash flow. Siapa saja bekerja pada perusahaan pekerja rendahan sampai manajer dan pemegang perusahaan pasti memiliki kaitan terhadap bidang akuntansi. Semakin meningkat jabatanya pada perusahaan harus tahu strategi dan terminologi akuntansi. Sedangkan kaitan inovasi wirausaha terhadap kinerja manajerial, menurut Seorang manajer bisa dikatakan seorang wirausaha, jika ia mampu menjalankan perbedaan-perbedaan yang besifat inovatif dengan proses produksi yang di manage olehnya. (Aditya Fitri Siregar, 2013).

Penelitian Terdahulu. Aditya Fitri Siregar/Erlina(2013) pada penelitian berjudul Pengaruh Pengetahuan Akuntansi dan kepribadian Wirausaha Terhadap Kinerja Manajerial Pada Perusahaan Jasa Di Kota Medan. Maksud dari penelitian ini yaitu supaya diketahui 
kaitan pada pengetahuan akuntansi dan kepribadain warausaha dengan kinerja manajerial pada perusahaan jasa di kota medan. Dalam penelitian ini peneliti menggunakan penelitian asosiatif. Hasil dari penelitian ini yaitu sifat kepribadain dan pengetahuan akuntansi seorang wirausaha memiliki kaitan positif dengan manajerial karena dapat meningkatkan kinerjanya pada perusahaan.

\section{METODE PENELITIAN}

Jenis Penelitian. Metode yang dipakai pada penelitian ini yaitu metode eksplanasi, karena penelitian ini memakai dua variabel. Metode eksplanasi yaitu suatu metode penelitian yang menggambarkan dua variabel yang diteliti, yaitu variable bebas dan variabel terikat yang menjelaskan kaitan atau pengaruh kedua variable tersebut. Singarimbun, (2003:46).

Tempat dan Waktu Penelitian. Penelitian ini mengambil data pada biro perjalanan (travel) di kota manado - Sulawesi Utara. Lamanya penelitian yang dilakukan pada skripsi ini yaitu paling lama dua bulan.

Prosedur Penelitian. Langkah - langkah dalam pengumpulan data yang dilakukan adalah sebagai berikut :

1. Penulis melakukan pengkajian awal dengan melakukan studi literatur baik studi kepustakaan maupun membaca melalui internet.

2. Turun langsung ke lapangan dan mengumpul informasi dan data-data yang terdapat pada Biro perjalanan travel di Kota Manado.

3. Mengadakan tanya jawab atau wawancara dengan pihak perusahaan.

4. Melakukan pengolahan data, membahasnya kemudian menarik kesimpulan dan memberikan saran-saran guna melengkapi penelitian.

Populasi dan Sampel. Adalah keseluruhan angka perhitungan dan pengukuran, kuantitatif atau kualitatif, dalam karakteristik dalam kumpulan objek yang jelas. (Husaini Usman. 2006 : 181). Sampel yaitu beberapa objek terpilih dalam semua objek di teliti maka dikatakan mencakup semua populasi (Notoatmojo, 2003). (Kuncoro2003:111) Populasi dalam penelitian ini ialah perusahaan jasa biro perjalanan (travel) yang terdapat di kota manado. Ada 62 travel agent dikota manado yang masi berjalan sampai sekarang ini, tetapi dengan waktu yang sangat terbatas peneliti hanya mendapatkan sampel sebanyak 30 travel agent saja. Sampel ini diambil berdasarkan asumsi atau pendapat dari Gay dan Diehl, yang menyatakan bahwa jumlah sampel minimal sebanyak 30 subyek.

\section{Metode Pengumpulan Data}

Jenis Data. Menurut Sinambela (2014:114), dilihat dari sifatnya data dapat dibedakan menjadi 2 kategori yaitu. Data kuantitatif, data yang diperoleh dengan bentuk angka atau yang diangkakan. Data yang dimiliki berupa bentuk informasi dan wawancara yang diadakan pada narasumber yaitu data kualitatif. Dalam penelitian ini penulis menggunakan data kualitatif.

Sumber Data. Sumber data pada skripsi ini yaitu data sekunder dan primer (Indrawan, dkk, 2014:141) Dalam penelitian ini, sumber data yang digunakan adalah data primer yang diperoleh langsung dari para responden yaitu manajer pada perusahaan jasa biro perjalanan (travel) di kota manado, serta data sekunder berupa referensi buku-buku cetak, internet,artikel beserta jurnal yang berkaitan dengan penelitian ini.

Teknik Pengumpulan Data. Pengambilan data yang dipakai pada skripsi ini adalah:

1. Dengan cara wawancara atau tanya jawab dengan pihak manajer perusahaan yang berkaitan dengan penelitian.

2. Pengumpulan data dengan mencari informasi menggunakan internet.

3. Melakukan pengamatan atau opservasi terhadap dokumen dan aktivitas terhadap data yang dibutuhkan. 
4. Teknik dokumentasi, yaitu mencari bahan tulisan perusahaan dan dokumen perusahaan yang berkaitan dengan penelitian.

Metode Analisis. Adapun metode analisis yang dipakai untuk membahas permasalahan yang ada yaitu

1. metode analisis deskriptif di mana metode yang sifatnya menggambarkan, menguraikan situasi, data dan menggambarkan, menggunakan data sebagaimana mestinya agar bisa diambil kesimpulan dalam menangani permasalahan yang akan timbul. (Walakandou, 2013:28).

2. Metode deduktif, yaitu suatu analisis yang dilakukan untuk membanding pengaruh penguasaan akuntansi dan inovasi wirausaha terhadap kinerja manajeriail dengan praktek yang terdapat dalam Biro Perjalanan (travel).

Definisi dan Pengukuran Variable. Penelitian ini berjudul "Pengaruh Penguasaan akuntansi dan Inovasi Wirausaha Terhadap Kinerja Manajerial pada Perusahaan Jasa di Kota Manado" . Pengukuran variabel ini dengan menggunakan pertanyaan-pertanyaan kuisioner dengan skala likert. Variable-Variabel diukur atau diteliti dalam penelitian ini adalah:

1. Variable Independen $(\mathrm{X})$ yaitu penguasan akuntansidan inovasi wirausaha

2. Variable Dependen (Y) yaitu kinerja manajerial

Variable-Variabel tersebut selanjutnya di devinisikan dan diukur sebagai berikut:

1. Penguasaan Akuntansi $\left(\mathrm{X}_{1}\right)$ ialah penguasaan suatu ilmu terhadap pemberitahuan yang dimiliki pelaporan keuangan terhadap orang yang memiliki kepentingan pada kegiatan ekonomi dan kondisi perusahaan. Orang yang menggunakan informasi itu ialah manajer dalam melakukan pengawasan perusahaan. Pertanyaan tentang penguasaan akuntansi sebanyak 5 pertanyaan.

2. Inovasi Wirausaha $\left(\mathrm{X}_{2}\right)$ ialah memberikan perubahan dengan pelayanan baru dan strategi yang lebih berguna dan dilakukan oleh wirausaha itu sendiri dengan memberikan kerja bagi semua orang. Pertanyaan tentang inovasi wirausaha berjumlah 5 pertanyaan yang terlampir dalam kuisioner diuji menggunakan skala likert satu sampai lima pertanyaan.

3. Kerja Manajerial (Y) ialah pengukuran seberapa efektif dan efisien manajer bekerja dalam memenuhi tujuan perusahaan. Prtanyaan tentang inovasi wirausaha seluruhnya berjumlah 5 pertanyaan yang terlampir dalam kuisioner dan diukur menggunakan skala likert (1-5).

\section{HASIL PENELITIAN DAN PEMBAHASAN \\ 4.1 Hasil Penelitian}

Perputaran perekonomian di Kota Manado tergolong berkembang pesat. Banyak wirausahawan baik dari luar maupun dalam Manado berlornba-lomba membangun usaha-usaha sesuai dengan kebutuhan masyarakat Kota Manado, maupun para tourist acing yang datang berkunjung. Salah satu contoh yaitu menjamurnya perusahaan jasa biro perjalanan (Travel). Menjarnurnya perusahaan jasa biro perjalanan (Travel agent) di Kota Manado mulanya ketika Manado menjadi tuan rurnah pelaksanaan program World Ocean Conference (WOC), Coral Triangel Summit (CTI) dan Sail Bunaken pada tahun 2009 lalu yang dihadiri oleh para perwakilan-perwakilan dari luar negeri maupun dalam negeri. Menurut data dari Dinas Pendapatan Daerah Kota Manado tahun 2009 dan data dari Lion Air Distric Manado tahun 2010, jumlah perusahaan jasa biro perjalanan (Travel) di kota Manado ada 62 perusahaan yang masih beroperasi sampai pada saat ini. Travel adalah merupakan perusahaan yang kegiatan usahanya berupa niengatur, dan menyediakan layanan berupa tiket bagi orang yang akan melakukan perjalanan memakai maskapai penerbangan. 
Deskripsi umum responden penelitian. Jumlah populasi sebanyak 62 Perusahaan jasa biro perjalanan (travel) di kota manado dan penyebaran kuesioner sebanyak 62 dan kuesioner yang dikembalilkan sebanyak 30 kuesioner sehingga 30 itulah yang di jadikan sampel penelitian. Peneliti melakukan pengumpulan data kepada 30 manajer yang bekerja pada Perusahaan Jasa biro perjalanan (Travel) di Kota Manado.

Tabel 1. Komposisi Responden Berdasarkan Tingkat Pendidikan

\begin{tabular}{ccr}
\hline Tingkat pendidikan & Jumlah & Prosentase \\
\hline SMA & 4 & $13.33 \%$ \\
Diploma & 6 & $20 \%$ \\
S1 & 20 & $66,67 \%$ \\
Total & 30 & $100 \%$ \\
\hline
\end{tabular}

Sumber Data: dari hasil olahan 2018

Pada Tabel 1 bisa dikatakan tinggihnya studi terakhir mereka sebagian besar yaitu Sarjana (S1) dan sekitar 20 karyawan memiliki nilai 66,67\%, kemudian Diploma sebanyak 6 karyawan dan memiliki nilai $20 \%$, kemudian tingginya pendidikan yang sangat sedikit adalah SMA yaitu sebanyak 4 orang dengan nilai prosentase sebesar 13,33\%.

Tabel 2. Komposisi Responden Berdasarkan Lama Bekerja

\begin{tabular}{ccc}
\hline Lama bekerja & Jumlah & Prosentase \\
\hline$>2$ Tahun & 30 & $100 \%$ \\
$<2$ Tahun & - & - \\
Total & 30 & $100 \%$ \\
\hline
\end{tabular}

Sumber Data: Hasil proses 2018

Pada Tabel 2 bisa dikatakan lama bekerja seluruh karyawan yang terlibat melewati 5 tahun yaitu sebanyak 30 karyawan dengan nilai sebesar $100 \%$.

\section{Hasil Analisis Data}

Uji Validitas dan Reliabilitas Data. Sebelum diadakan analisis regress untuk itu diadakan pengujian validitas dan reliabilitas. Selanjutnya ditampilkan hasil perhitungan uji validitas dan reliabilitas variabel Penguasaan Akuntansi yang terdiri dari 5 pertanyaan.

Tabel 3. Uji Validitas dan Reliabilitas Variabel Penguasaan Akuntansi (X1)

\begin{tabular}{cccc}
\hline No & Pertanyaan & $\begin{array}{c}\text { Corrected item - } \\
\text { Total Correlation }\end{array}$ & Keterangan \\
\hline 1. & Pertanyaan 1 & 0,809 & Akurat \\
2. & Pertanyaan 2 & 0,740 & Akurat \\
3. & Pertanyaan 3 & 0,729 & Akurat \\
4. & Pertanyaan 4 & 0,727 & Akurat \\
5. & Pertanyaan 5 & 0,813 & Akurat \\
\hline
\end{tabular}

Alpha Cronbach $=0,909$

$\mathrm{r}_{\text {tabel }}=0,361$

Sumber : Hasil Olahan Data 
Dari Tabel 3 uji validitas dengan variabel Penguasaan Akuntansi menggunakan 5 butir item hasilnya seluruhnya akurat dan berada diatas nilai kritisnya $r_{\text {tabel }}=0,361$ maka butir instrument itu bisa dipakai dalam menguji variabel penelitian.

Tabel 4. Uji Validitas dan Reliabilitas Variabel Inovasi Wirausaha (X2)

\begin{tabular}{cccc}
\hline No & Pertanyaan & $\begin{array}{c}\text { Corrected item } \\
\text { Total Correlation }\end{array}$ & Informasi \\
\hline 1. & P-1 & 612 & Akurat \\
2. & P-2 & 712 & Akurat \\
3. & P-3 & 626 & Akurat \\
4. & P-4 & 763 & Akurat \\
5. & P-5 & 637 & Akurat \\
\hline
\end{tabular}

Alpha Cronbach $=0,854$

$\mathrm{r}_{\text {tabel }}=0,361$

Sumber : Hasil Olahan Data

Dari Tabel 4 ternyata uji validitas terhadap variable Inovasi Wirausaha menggunakan 5 butir item hasilnya seluruhnya akurat dan bertempat diatas hasil rendahnya $r_{\text {tabel }}=$ 0.361 maka butir instrument itu bisa dipakai dalam menguji variabel penelitian. Sedangkan uji reliabilitas diperoleh Alpha Cronbach $=0,854$ atau berada diatas nilai kritis yang diinformasikan sebesar 0,6 maka variable Inovasi Wirausaha dikatakan reliabel, berikut dapat dilihat uji validitas variabel Kinerja Manajerial (Y):

Tabel 5. Uji Validitas Variabel Kinerja Manajerial (Y)

\begin{tabular}{cccc}
\hline No & Pertanyaan & $\begin{array}{c}\text { Corrected item - } \\
\text { Total Correlation }\end{array}$ & Informasi \\
\hline 1. & P-1 & 748 & Akurat \\
2. & P-2 & 72 & Akurat \\
3. & P-3 & 704 & Akurat \\
4. & P-4 & 618 & Akurat \\
5. & P-5 & 510 & Akurat \\
\hline
\end{tabular}

Alpha Cronbach $=0,850$

$\mathrm{r}_{\text {tabel }}=0,361$

$\mathrm{r}_{\text {tabel }}=0,361$

Sumber : Hasa Olahan Data

Dari Tabel 5 hasil uji validitas pada variabel Kinerja Manajerial menggunakan lima butir item hasilnya akurat dan bertempat diatas hasil minimnya \%the $=0.361$ maka butir instrument itu bisa dipakai dalam menguji variable penelitian.

Statistik deskriptif. Dalam memakai program SPSS Version 12.0, jadi rata-rata hitung dan standar deviasi pada tiap-tiap variabel seperti yang telah ditunjukkan pada Tabel 6 Descriptive statistics sebagai berikut :

Tabel 6. Descriptive Statistics

\begin{tabular}{lrrr}
\hline & Mean & Std. Deviation & N \\
\hline Kinerja Manajerial & 19.1333 & 2.41737 & 30 \\
Penguasaan Akuntansi & 19.4000 & 3.45014 & 30 \\
Inovasi Wirausaha & 19.3000 & 2.53459 & 30 \\
\hline
\end{tabular}

Sumber : Hasil Olahan Data 
Berdasarkan Tabel 6, maka dapat dikatakan :

1) Total hitung dengan standar deviasi dari variable Penguasaan Akuntansi (X1). Pada variable bebas Penguasaan akuntansi $\left(\mathrm{X}_{1}\right)$ didapat total hitung jumlah hasil yaitu 19,4000 dengan standar deviasi sebesar 3,45014 ddengan banyaknya yaitu 30.

2) Total jumlah dengan standar deviasi dari variable Inovasi Wirausaha $\left(\mathrm{X}_{2}\right)$. Untuk variabel bebas Inovasi Wirausaha $\left(\mathrm{X}_{2}\right)$ didapatkan total perhitungan jumlah hasil yaitu 19,3000 sedangkan standar deviasi sebanyak 2,53459 maka jumlah hasil sebesar 30 .

3) Total jumlah dengan standar deviasi dalam variabel Kinerja Manajerial (Y). dengan variable Kinerja Manajerial (Y) didapatkan total jumlah hasil perhitungan sebanyak 19.1333 dan standar deviasinya 2,41737 sedangkan jumlah sebesar 30.

Uji Asumsi Klasik. Dalam memperoleh hasil regresi linier dengan bagus harus menggunakan pengujian asumsi klasik, yaitu :

\section{Uji Asumsi Klasik Multikolinearitas}

Tabel 7. Uji Multikolinearitas

\section{Unstandardized Standar \\ Statistik collinearity Coefficients koefisien}

\begin{tabular}{|c|c|c|c|c|c|c|}
\hline Bentuk & b & $\begin{array}{c}\text { S. } \\
\text { Error }\end{array}$ & Beta & Sig. & Tolerance & VIF \\
\hline $1 \quad$ (konstan) & 3,099 & 1.405 & & 2.205 .036 & & \\
\hline $\begin{array}{l}\text { Penguasaan } \\
\text { Akuntansi }\end{array}$ & .230 & 096 & .329 & 2.387.024 & .292 & 3.426 \\
\hline Inovasi Wirausaha & .599 & .131 & .628 & 4.562 .000 & .292 & 3.426 \\
\hline
\end{tabular}

a. Dependent Variable: Kinerja Manajerial

Slumber : Data Hasil Olahan

Sesuai hasil Statistik collinearity bisa dilihat dalam output coefficient model, dibilang belum terdapat unsur-unsur multikolinearitas jika nilai VIF $<10$. Hasil penjumlahan menimbulkan nilai VIF dalam variabel penguasaan akuntansi sebanyak 3,426 dengan inovasi wirausaha sebesar 3,426 jadi bisa dikatakan belum terdapat unsur multikolinearitas pada bentuk regresi di atas.

Uji Asumsi Klasik Autokorelasi. Uji autokorelasi menggunakan nilai DurbinWatson (DW). Sccara umum dengan dapat diambil patokan dari (Santoso : 2000) :

1. Nilai $\mathrm{d}-\mathrm{w}$ kurang dari dua yaitu timbul autokorelasi yang baik:

2. Nilai d - w di sela - sela kurang dari dua dengan lebih dari dua yaitu tanpa autokorelasi.

3. Nilai $\mathrm{d}-\mathrm{w}$ melebihi dua yaitu terdapat autokorelasi.

Dan dalam tabel bisa dikatakan maka hasil Durbin - Watson (DW) dimiliki sebanyak 1.923 maka bisa dikatakan tanpa ada autokorelasi. 


\section{Regresi Linear Berganda}

Tabel 8. Coefficients ${ }^{\mathrm{a}}$

\begin{tabular}{|c|c|c|c|c|c|c|c|c|}
\hline \multirow[b]{2}{*}{ Model } & \multicolumn{2}{|c|}{$\begin{array}{l}\text { Unstandardized } \\
\text { Coefficients }\end{array}$} & \multirow{2}{*}{$\begin{array}{c}\begin{array}{c}\text { Standardized } \\
\text { Coefficients }\end{array} \\
\text { Beta } \\
\end{array}$} & \multirow[b]{2}{*}{$t$} & \multirow[b]{2}{*}{ Sig. } & \multicolumn{3}{|c|}{ Collinearity Statistics } \\
\hline & B & Std. & & & & Tolerance & V I & I F \\
\hline 1 (Constant) & 3.099 & 1.405 & & 2.205 . & 036 & & & \\
\hline Penguasaan Akuntansi & .230 & .096 & .329 & 2.387 & .024 & .292 & & 3,426 \\
\hline inovasi Wirausaha & .599 & .131 & .628 & 4.562 & .000 & .292 & & 3.426 \\
\hline
\end{tabular}

a. Variabel Dependent: Kinerja Manajerial

Sumber : Hasil Olahan Data

Pada penelitian ini, pengujian hipotesis dilaksanakan untuk membuktikan pengaruh Penguasaan Akuntansi, dan Inovasi Wirausaha pada Kerja Manajerial. Analisis dipakai pada hasil penelitian ini ialah statistik inferen seperti regresi linear berganda pada alat analisis peramalan nilai pengaruh beberapa variable bebas pada suatu variable terkait agar bisa memberi bukti ada atau tidak kaitan fungsional atau kaitan kausa dalam variable bebas dan variable terikat.

Correlation Coefficient $(\mathbf{R})$ and Determination Coefficient $\left(\mathbf{R}^{\mathbf{2}}\right)$. Analisis koefisien korelasi (R) dipakai dalam menguji keeratan kaitan pada variable bebas (x) kepada variable terikat (y), dengan itu menghitung besar kecilnya kaitan Penguasaan Akuntansi $\left(\mathrm{X}_{1}\right)$, dengan Inovasi Wirausaha $\left(\mathrm{X}_{2}\right)$ dan Kinerja Manajerial $(\mathrm{Y})$.

Table 9. Correlations

\begin{tabular}{llrrr}
\hline \multirow{2}{*}{ Pearson } & & Kinerja & Penguasaan & Inovasi \\
\cline { 3 - 5 } & Kinerja Manajerial & 1000 & .857 & 905 \\
\multirow{3}{*}{ Sig. (1-tailed) } & .857 & 1.000 & .841 \\
& Penguasaan & .905 & .841 & 1.000 \\
& Inovasi Wirausaha & & 000 & .000 \\
$\mathrm{~N}$ & Kinerja Manajerial & .000 & & 000 \\
& Penguasaan & .000 & .000 & 30 \\
& lnovasi Wirausaha & 30 & 30 & 30 \\
& Kinerja Manajerial & 30 & 30 & 30 \\
\hline
\end{tabular}

Sumber : Data Hasil Olahan

Sesuai penjumlahan dalam penelitian ini dalam memakai program SPSS dalam tabel bagian Correlations bisa diperhatikan maka koefisien korelasi linear yang didapatkan diantara Penguasaan Akuntansi $\left(\mathrm{x}_{1}\right)$ dan Kinerja Manajerial (y) yaitu sebanyak 0,857 maka tanpa ada kaitan yang bertolak belakang atau negatif sebesar 0,857 dan koefisien korelasi linear yang dihasilkan pada Inovasi Wirausaha $\left(\mathrm{x}_{2}\right)$ dan Kinerja Manajerial (y) sebesar 0,905 artinya juga tidak mempunyai kaitan berlawanan atau negatif sebanyak 0,905 .

\subsection{Pembahasan}

Pengaruh Penguasaan Akuntansi dan Inovasi Wirausaha Terhadap Kinerja Manejerial Pada Perusahaan Jasa Biro Perjalanan (Travel) di Kota Manado. Berdasarkan hasil penelitian dengan memakai program SPSS yang ada dalam table 4.9 dalam Correlations bisa dikatakan bahwa koefisien korelasi linear yang dimilki dalam 
Penguasaan Akuntansi(X1) dengan Kinerja Manajerial (Y) yaitu sebanyak 0,857 sehingga tidak mempunyai kaitan yang bertentangan atau negatif yaitu 0,857 dan koefisien korelasi linear yang dimiliki dari Inovasi Wirausaha (X2) dengan Kinerja Manajerial (Y) yaitu sebanyak 0,905 maka tidak ditemukan adanya kaitan yang bertentangan dan negatif sebanyak 0,905. Variabel penguasaan akuntansi dan inovasi wirausaha mempunyai hubungan yang sangat kuat sekali kepada kerja manajer pada perusahaan jasa biro perjalanan (Travel) di Kota Manado. Oleh karena itu bisa dikatakan bahwa setiap kali terjadi perubahan Penguasaan Akuntansi dan Inovasi Wirausaha maka dapat mempengaruhi Kinerja Manajerial pada Perusahaan Jasa Biro Perjalanan (Travel) di Kota Manado.

\section{KESIMPULAN DAN SARAN}

\subsection{Kesimpulan}

1. Dilihat dalam penelitian maka bisa disimpulkan bahwa menolak $\mathrm{H}_{\mathrm{o}}$ dan menerima $\mathrm{H}_{\mathrm{a}}$ atau Penguasaan Akuntansi berpengaruh terhadap Kinerja Manajerial pada Perusahaan Jasa Biro Perjalanan (Travel) di Kota Manado.

2. Dilihat dalam hasil uji t dari table diatas bisa dikatakan menolak $\mathrm{H}_{\mathrm{o}}$ dan menerima $\mathrm{H}_{\mathrm{a}}$ atau dapat disimpulkan bahwa Inovasi Wirausaha berpengaruh terhadap Kinerja Manajerial pada Perusahaan Jasa Biro Perjalanan (Travel) pada Kota Manado.

3. Berdasarkan hasil perhitungan dengan memakai bantuan program SPSS yang ada pada tabel 4.12 bagian Correlations, maka dapat disimpulkan bahwa 2 variable Penguasaan Akuntansi dengan Inovasi Wirausaha mempunyai kaitan kuat sekali dengan Kinerja Manajerial dalam Perusahaan Jasa Biro Perjalanan (Travel) di Kota Manado.

\subsection{Saran}

Adapun saran yang bisa di masukan dalam penelitian tersebut yaitu:

1. Peneliti berikutnya bisa perluas araea survey dan mencoba untuk daerah diluar kota Manado, agar dapat memiliki objek lebih dari ini dengan hasil lebih baik dan teruji.

2. Klasifikasi perusahaan jasa pada skripsi ini berikutnya diperbanyak dan klasifikasi jasa yang lain.

3. Peneliti selanjutnya bisa mennggunakan variable - variable sebagai predicator perkembangan kerja manager, yaitu cara memimpin manager, semangat kerja, rasa kompeten, dan variable lainya dan bisa memengaruhi kerja manager satu perusahaan.

\section{DAFTAR PUSTAKA}

Arman Hakim Nasution dan Hermawan Kartajaya. Inovasi. Penerbit Andi 2018. Yogyakarta. Carl s. Warren, dkk. Akuntansi Pengantar, Penerbit Salemba Empat, Edisi ke-25, tahun 2014. Husaini Usman. (2006). Pengantar Statistika. Jakarta : PT Bumi Aksara.

Hansen D.R, dan Maryanne M. Mowen, 2009. Akuntansi Manajerial Penerbit Salemba 4 Buku 2 Edisi 8/,

Krismiaji Y. Ani Ariani. Akuntansi Manajemen. Penerbit dan percetakan, Sekolah Tinggi Ilmu Manajemen YKPN Edisi ke 2.

Lion Air Distric Manado, 2010, List Travel Agent Manado.

Peter Drucker (2011), yang dimuat dalam bukunya innovation dan entrepreneuship.

Sadono Sukirno, et al. Pengantar Bisnis, Edisi Pertama, 2004. Penerbit Kencana. Jakarta.

Sadono Sukirno, et al. Pengantar Bisnis. Penerbit Kencana, 2004. Jakarta.

Soekidjo Notoatmodjo. 2003. Metodologi Penelitian Kesehatan. Jakarta : Rineka Cipta.

Thomas Zimmerer, 1996. Manajemen Entreoreneurship. Dr. Saban Echdar, SE.,M.Si

Penerbit Andi, 2013. Yogyakarta.

Warren dkk, 2014. Pengantar Akuntansi. Penerbit Salemba 4, edisi ke 25. 